\title{
Smoking prevalence and attributable deaths in Thailand: predicting outcomes of different tobacco control interventions
}

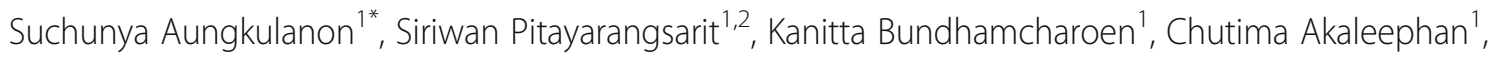
Virasakdi Chongsuvivatwong ${ }^{3}$, Ratsida Phoncharoen ${ }^{1}$ and Viroj Tangcharoensathien ${ }^{1}$

\begin{abstract}
Background: Despite substantial positive impacts of Thailand's tobacco control policies on reducing the prevalence of smoking, current trends suggest that further reductions are needed to ensure that WHO's 2025 voluntary global target of a 30\% relative reduction in tobacco use is met. In order to confirm this hypothesis, we aim to estimate the effect of tobacco control policies in Thailand on the prevalence of smoking and attributed deaths and assess the possibilities of achieving WHO's 2025 global target. This paper addresses this knowledge gap which will contribute to policy control measures on tobacco control. Results of this study can help guide policy makers in implementing further interventions to reduce the prevalence of smoking in Thailand.
\end{abstract}

Method: A Markov chain model was developed to examine the effect of tobacco control policies, such as accessibility restrictions for youths, increased tobacco taxes and promotion of smoking cessation programs, from 2015 to 2025. Outcomes included smoking prevalence and the number of smoking-attributable deaths. Due to the very low prevalence of female smokers in 2014, this study applied the model to estimate the smoking prevalence and attributable mortality among males only.

Results: Given that the baseline prevalence of smoking in 2010 was $41.7 \%$ in males, the target of a 30\% relative reduction requires that the prevalence be reduced to $29.2 \%$ by 2025 . Under a baseline scenario where smoking initiation and cessation rates among males are attained by 2015, smoking prevalence rates will reduce to $37.8 \%$ in 2025. The combined tobacco control policies would further reduce the prevalence to 33.7\% in 2025 and 89,600 deaths would be averted.

Conclusion: Current tobacco control policies will substantially reduce the smoking prevalence and smokingattributable deaths. The combined interventions can reduce the smoking prevalence by 19\% relative to the 2010 level. These projected reductions are insufficient to achieve the committed target of a $30 \%$ relative reduction in smoking by 2025. Increased efforts to control tobacco use will be essential for reducing the burden of noncommunicable diseases in Thailand.

Keywords: Tobacco, Policy, NCD global target, Thailand

\footnotetext{
* Correspondence: suchunyaa@gmail.com

${ }^{1}$ International Health Policy Program, Ministry of Public Health, Nonthaburi,

Thailand

Full list of author information is available at the end of the article
}

(c) The Author(s). 2019 Open Access This article is distributed under the terms of the Creative Commons Attribution 4.0 International License (http://creativecommons.org/licenses/by/4.0/), which permits unrestricted use, distribution, and reproduction in any medium, provided you give appropriate credit to the original author(s) and the source, provide a link to the Creative Commons license, and indicate if changes were made. The Creative Commons Public Domain Dedication waiver (http://creativecommons.org/publicdomain/zero/1.0/) applies to the data made available in this article, unless otherwise stated. 


\section{Background}

Non-communicable diseases (NCDs) are the leading causes of death globally. In 2011, the United Nations General Assembly adopted a political declaration which committed its member states to focus on the prevention and control of NCDs [1]. Their goal is to achieve a $25 \%$ reduction of premature mortality due to NCDs by 2025 (the $25 \times 25$ target). The World Health Organization identified six targets for the prevention and control of risk factors for NCDs and two targets on availability and use of essential medicines and technologies. One of these targets is a $30 \%$ relative reduction in the prevalence of current tobacco use in persons aged 15 or more years between 2010 and 2025. Global modelling shows that tobacco use will have the largest effect in terms of reducing premature mortality from NCDs [2]. To plan and prioritize national tobacco control strategies, it is important for the Thai government to know whether or not the 30\% target can be achieved and if not, what additional or enhanced policy interventions are needed to achieve the target [3]. This paper addresses this knowledge gap which will contribute to policy control measures on tobacco control.

NCDs have become a critical public health issue for Thailand. Deaths from NCDs accounted for $74 \%$ of the total 539,000 deaths in Thailand in 2016 and are predicted to continue to increase rapidly [4]. Tobacco use is an important modifiable risk factor as available interventions have been proven to be effective and 1 in 6 deaths from NCDs are caused by tobacco [5]. Smoking is the first leading risk factor for early death and disability in Thailand, particularly for people with cancer, pulmonary complications and heart disease. Almost 50,000 people die due to tobacco use each year [6]. The social costs of smoking were estimated at 2.18 billion US dollars, approximately $0.78 \%$ of the GDP, while the tobacco industry produced only $0.50 \%$ of the total GDP [7].

Having ratified the Framework Convention on Tobacco Control, Thailand has actively implemented many of the tobacco control policies which has shown remarkable success in reducing overall smoking rates from 23\% in 2003 to $19 \%$ in 2017 [8, 9]. Despite some successes, challenges remain; for example, the increasing smoking prevalence rates among youth, the high proportion of roll-your-own cigarettes in adults, an ineffective regulation of tobacco sales to underage youths, second hand smoking in households, increasing gaps in the smoking rates between males and females, emergence of electronic cigarette use among youth, and difficulties in eliminating the illicit tobacco trade [10-13]. This suggests that the previous tobacco control policies might be less effective in some populations and/or not last very long. The Tobacco Products Control Act 2017 (BE 2560) entered into force on 4 July 2017. The law increased the minimum age for purchasing tobacco products from 18 to 20 years and updated the legislation on tobacco advertising, promotion and sponsorship among other regulations [14] This is expected to strengthen the prevention of youth smoking and secondhand smoking.

Despite a prior study in Thailand estimating that a $25 \%$ reduction in the prevalence of smoking during 1991-2006 was due to four main policies; increased cigarette taxes, smoke-free public areas, bans on advertising tobacco products, and the addition of warning labels on cigarette packs [15], we are not confident that the implementation of the Tobacco Products Control Act 2017 can encourage Thai residents to quit smoking, or deter them from initiating smoking, to such a level that would ensure the whole country achieves a $30 \%$ reduction in smoking prevalence by 2025 .

In order to forecast the achievable level, this study uses a modeling method to project the smoking prevalence and attributable deaths in the previous policy context and six new scenarios including effects of the new law on youth smoking prevention, other feasible policies, and other effects of the Tobacco Product Control Act.

\section{Method}

\section{Smoking model}

We used a Markov chain model to estimate the projected smoking prevalence and attributed mortality in 2025. A discrete-time Markov chain is a stochastic process, which consists of a finite number of states and transition probabilities among the different states. In this study, the model begins by using data from the base year of 2015 with the population classified into three states: never, current, and former smokers stratified by 5 -year age groups and gender.

In the Markov model, death is the final absorbing state, a state in which people can enter but cannot leave. The prevalence of never, current and former smokers stratified by age and gender from 2015 to 2025 was estimated using four parameters: (1) the cessation rate among current smokers; (2) the smoking initiation rate; (3) the relapse smoking rate among quitters; and (4) the probabilities of death for each group. The populations aged 15 years or more, based on the Thai census, were entered into the model annually and assigned as never smokers. Figure 1 shows a transition diagram for each of the states in the model.

We developed two models which estimate the projected smoking prevalence and attributed mortality in 2025. The 2015 baseline model refers to the current smoking initiation and cessation rate. Several forecasting models were constructed to predict the effect of different interventions on the prevalence of smoking and attributed mortality. Table 1 presents the probabilities of moving from one state into another state for the next year. 


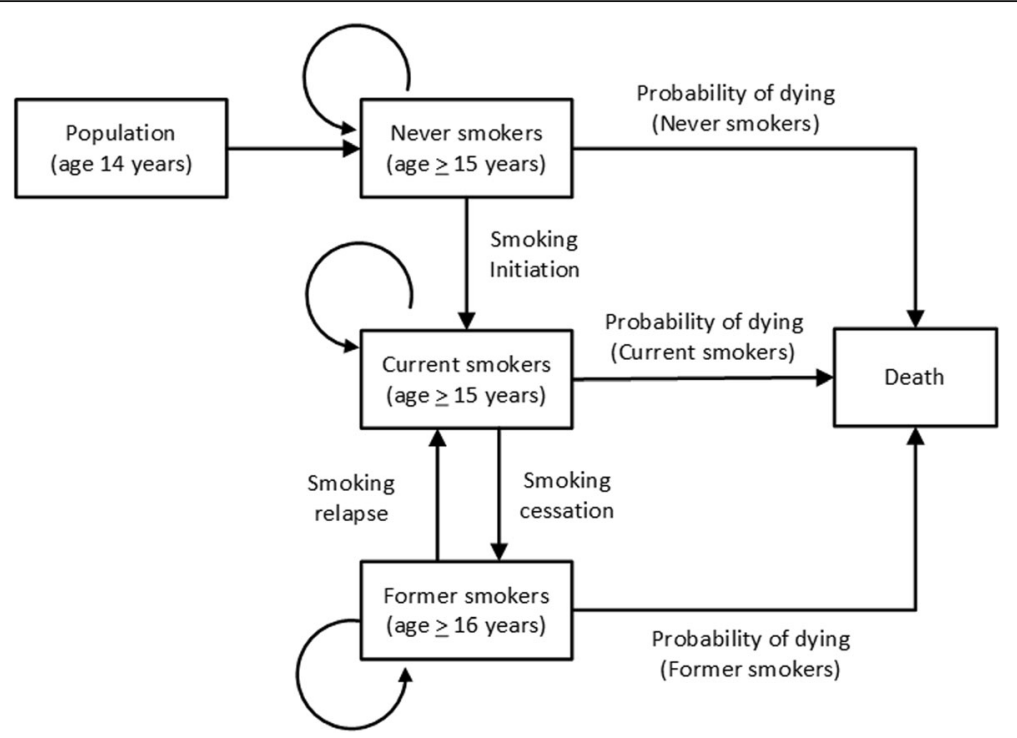

Fig. 1 Overview of 2015 base Markov chain model used to predict the prevalence of smoking and attributed mortality in 2025

\section{Data sources}

The smoking prevalence, cessation rate, initiation rate, and other related parameters were drawn from the most recent smoking and drinking behavior survey conducted regularly by the National Statistics Office (NSO) and expressed as percentages. All-cause mortality data for 2015 was obtained from the Strategy and Planning Division, Ministry of Public Health. The mid-year population data before 2015 were obtained from Ministry of Interior and the population projections for years after 2015 were obtained from Office of the National Economic and Social Development Board. SAS software version 9.4 was used to analyze the data.

\section{Parameters}

\section{Smoking status}

Current smokers were those who reported smoking either regularly or occasionally. Former smokers were those who reported ever smoking in their lifetime but were not current smokers.

\section{Cessation rate}

Annual cessation rates were measured as the number of current smokers in each year who became non-smokers the following year divided by the number of current smokers in each previous year. Cessation rates were estimated for each age and gender group.

cessation rate $=$ former smokers who had not smoked for 12-23 months former smokers who had not smoked for 12-23 months + current smokers who have smoked $\geq 24$ months

\section{Initiation rate}

Annual initiation rates were measured as the number of current smokers in each year who did not smoke in the previous year divided by the number of non-smokers in the previous year. Initiation was modeled from age 15 to 24 years.

initiation rate $=$

current smokers who have smoked $<12$ months current smokers who have smoked $<12$ months + never smokers

Table 1 Transition matrix showing probabilities of movement from one state to another in the cycle of smoking behavior

\begin{tabular}{|c|c|c|c|c|}
\hline \multirow[t]{2}{*}{ Current year } & \multicolumn{4}{|l|}{ Next year } \\
\hline & Never smoker & Current smoker & Former smoker & Death \\
\hline Never-smoker (NS) & 1-initiation-pdying a (NS) & Initiation & 0 & pdying $^{\mathrm{a}}$ (NS) \\
\hline Current-smoker (CS) & 0 & 1-cessation-pdying ${ }^{\mathrm{a}}$ (CS) & cessation & pdying $^{\mathrm{a}}(\mathrm{CS})$ \\
\hline Former-smoker (XS) & 0 & relapse & 1-relapse-pdying ${ }^{a}$ (XS) & pdying $^{a}(X S)$ \\
\hline Death & 0 & 0 & 0 & 1 \\
\hline
\end{tabular}

apdying probability of dying 


\section{Relapse rate}

There are empirical challenges in measuring relapse rates. Since the survey did not contain a question asking for the specific year that a current smoker quit smoking, we used the annual incidence of smoking relapse after 1 year from a meta-analysis [16].

\section{Probability of dying from smoking}

The annual probabilities of dying among the never, current and former smokers were estimated from the age and gender-specific mortality rates. These mortality rates were calculated from 1) all-cause mortality rates from Thai population life tables for 2015, and 2) the relative risk of mortality from smoking from the American Cancer Society (ACS) Cancer Prevention Study phase two data (CPS-II) [17]. The formulas applied to estimate the probabilities of dying for never, current and former smokers are shown in the Appendix.

\section{Model outcomes}

The two primary outcomes from the model were annual smoking prevalence and smoking attributable deaths stratified by age and gender. We compared the effects of different tobacco control interventions with the 2015 baseline scenario. The cumulative number of lives saved was defined as the difference between the 10-year cumulative number of smoking attributable deaths from the 2015 baseline scenario and that calculated from policy interventions.

\section{Tobacco control policy effects}

The effects of control policies were assessed based on the effectiveness of tobacco control interventions, which was based on the number of smokers who quit, the number of non-smokers prevented from initiating smoking, and the coverage of the target population under the control policy. For example, the effect of cessation policies on increased cessation rate is equal to $1+$ (intervention coverage rate $\times$ success rate).

\section{Scenarios of tobacco control interventions Baseline scenario}

In the 2015 baseline scenario, age-specific initiation and cessation rates were estimated from the smoking and drinking behavior survey conducted by the NSO. We assumed that initiation and cessation rates remained constant throughout the projection period between 2015 and 2025.

\section{Scenario 1: policies involving restricting access to tobacco among youth}

Prohibition of tobacco sales to youths under the age of 18 years was implemented in 1992. In 2017 the minimum legal age for purchasing cigarettes was increased to 20 years. However, monitoring, surveillance and enforcement are largely ineffective as recent studies have reported that more than half of smokers aged under 18 years buy cigarettes [18]. Effective interventions in prohibiting smoking include increased taxes and retail prices of tobacco products beyond the youths purchasing capacity, anti-smoking mass media campaigns, smoke-free policies, school curricula on the mortality impact of tobacco, and restricting minors from purchasing tobacco-related products $[19,20]$. These policies have already had a substantial impact in Thailand. Further gains might be realized by implementing stricter youth access policies. Our model assumed that youth access interventions could reduce the smoking initiation rate among adolescents by a maximum of $50 \%$, and this effect remained constant over the entire projection period.

\section{Scenario 2: annual increases of tobacco taxes and prices by} $15 \%$

Most studies in low- and middle-income countries have shown that a $10 \%$ increase in the price of cigarettes will reduce consumption by $4-6 \%$ with younger smokers being more price-sensitive than older smokers [21]. Empirical evidence suggests that about half of the reduction in cigarette consumption is the result of current smokers quitting altogether and another half results from the remaining smokers reducing their smoking frequency [22]. However, price effects on smoking initiation among youths have been found to have little impact [23].

Regular price increases above the inflation rate and purchasing power are effective in curbing smoking demand [24]. One study in 2009 found that despite an increase of cigarette prices by $8.7 \%$ in real terms, cigarette consumption actually increased [25]. In this study, in line with experts' recommendations, we assumed a 15\% annual increase in tobacco tax and applied a -0.5 price elasticity of smoking consumption. We further assumed a double effect on young adults aged 15-24 years. Therefore, the model specification is that a $15 \%$ annual price increase will increase the cessation rate by $3.75 \%$ among those aged 25 years or more and $7.5 \%$ among those aged less than 25 years.

\section{Scenario 3: increased coverage of a national telephone quit-line}

Establishment of the Thailand National Quit-line center in 2009 expanded smokers' access to behavioral counseling services to help them quit smoking. A well-publicized, multi-session proactive quit-line was estimated to reach between 1 and $4 \%$ of smokers over a 1 year period [26-28]. Coverage of the quit-line is estimated to reach $6-8 \%$ of all smokers [29]. The International Tobacco Control (ITC) Survey reported 
that globally, Dutch smokers had the highest use of a quit-line (around 12\% of smokers) while in Thailand the figure was only 3\% [30]. Cochrane Systematic Reviews estimated that a quit-line can increase the smoking cessation rates by between 20 and 36\% [31]. In this study, we used data from a study by Meeyai which reported a 12-month effectiveness of $19.5 \%$ for Thailand's smoking cessation quit-line [32] and assumed effects remained constant over the projection period. It was further assumed that the intervention can reach a maximum of $12 \%$ of current smokers.

\section{Scenario 4: increased coverage of a health facility-based brief advice intervention on smoking cessation}

Brief advice is one of the most cost-effective disease prevention interventions [33], and is feasible to integrate into primary health care centers due to its relatively low cost. Cochrane Systematic Reviews estimated that a brief advice intervention can increase the rate of smoking cessation by up to 66\% [34]. Despite these guidelines and its cost-effectiveness, this intervention is largely neglected by health professionals in low- to middle-income countries. Smokers are not offered cessation advice in clinical encounters [35]. The ITC Survey reported large variations in coverage of brief advice by health professionals, ranging from less than $10 \%$ in New Zealand to over $50 \%$ in the USA [30]. Thailand's Health Welfare Survey reported that $29 \%$ of the population had visited a health facility during the past 30 days prior to the survey. We assumed that $30 \%$ of smokers visit a healthcare provider of which all received advice to quit smoking, and the smoking cessation rate from this intervention was $66 \%$.

\section{Scenario 5: combined effects of policy interventions}

When more than one policy is in effect, the rates of reduction in smoking initiation and cessation can be multiplicative, implying that the effect of an additional policy is synergized and increases the effect of another policy.

\section{Scenario 6: theoretical scenarios}

In the theoretical scenario, we assumed that the smoking initiation intervention could reduce smoking initiation in youths and young adults to zero. We also assumed that $100 \%$ of the current smokers were covered by the cessation interventions using the telephone quit-line and health facility based brief advice offered by health professionals.

\section{Model validation}

To test the validity of our estimates, smoking rates predicted by the model were compared to the observed prevalence rates from national smoking and drinking survey data reported by the NSO. We use these models to project the gender-specific smoking prevalence for the period between 2007 and 2014 compared with the survey data in 2007 and 2011 on smoking prevalence.

\section{Results}

\section{Validation: predictions of smoking prevalence}

The predicted prevalence of smoking for males in 2007, 2011, and 2014 were similar to the prevalence from the smoking and drinking behavior survey and showed a similar pattern of decline. For females the smoking prevalence was $2.4 \%$ in $2007,2.1 \%$ in 2011 , and $2.2 \%$ in 2014. Due to the low prevalence of female smokers, this study applied the model to estimate the smoking prevalence and attributable mortality among males only.

\section{Baseline scenario: input parameters and projection of smoking prevalence Smoking prevalence}

In the smoking and alcohol consumption behavior survey, the prevalence of current smoking for those aged 15 years and over was $40.8 \%$ ( $95 \%$ confidence interval [CI]: 39.4-41.8) among males and 2.2\% (95\% CI: $1.9-$ 2.5) among females. Table 2 shows estimates of the national prevalence of never, current, and former smokers stratified by age and sex.

Figure 2 shows the number of smokers and quitters in 2014 among males aged 15 years and over stratified by smoking duration for which the annual cessation and initiation rates are estimated.

\section{Annual cessation rate}

In the tobacco consumption survey, there were 3.4 million former smokers of which $65.9,10.5$ and $23.7 \%$ had quit smoking for less than 12 months, between 12 and 23 months, and 24 months or more, respectively. The annual smoking cessation rate among male smokers was $3.3 \%$. As shown in Table 3, rates increased with increasing age with the lowest cessation rate of $1.5 \%$ found in those aged 20-34 years.

\section{Annual initiation rates}

The annual smoking initiation rates among males aged $15-19,20-24,25-29$ and 30 or more years were 5.0, 2.7, 0.8 and $0.1 \%$, respectively.

\section{Prediction of smoking prevalence under baseline scenario}

Figure 3 shows the trend in smoking prevalence for males. Under the baseline scenario in which cessation and smoking initiation rates continued unchanged, the smoking prevalence in males is expected to decrease from $40.8 \%$ in 2015 to $37.8 \%$ in 2025 . Despite this reduced prevalence, the estimated number of current 
Table 2 Prevalence of smoking profiles (\%) by gender and age group, Thailand, 2014 household survey

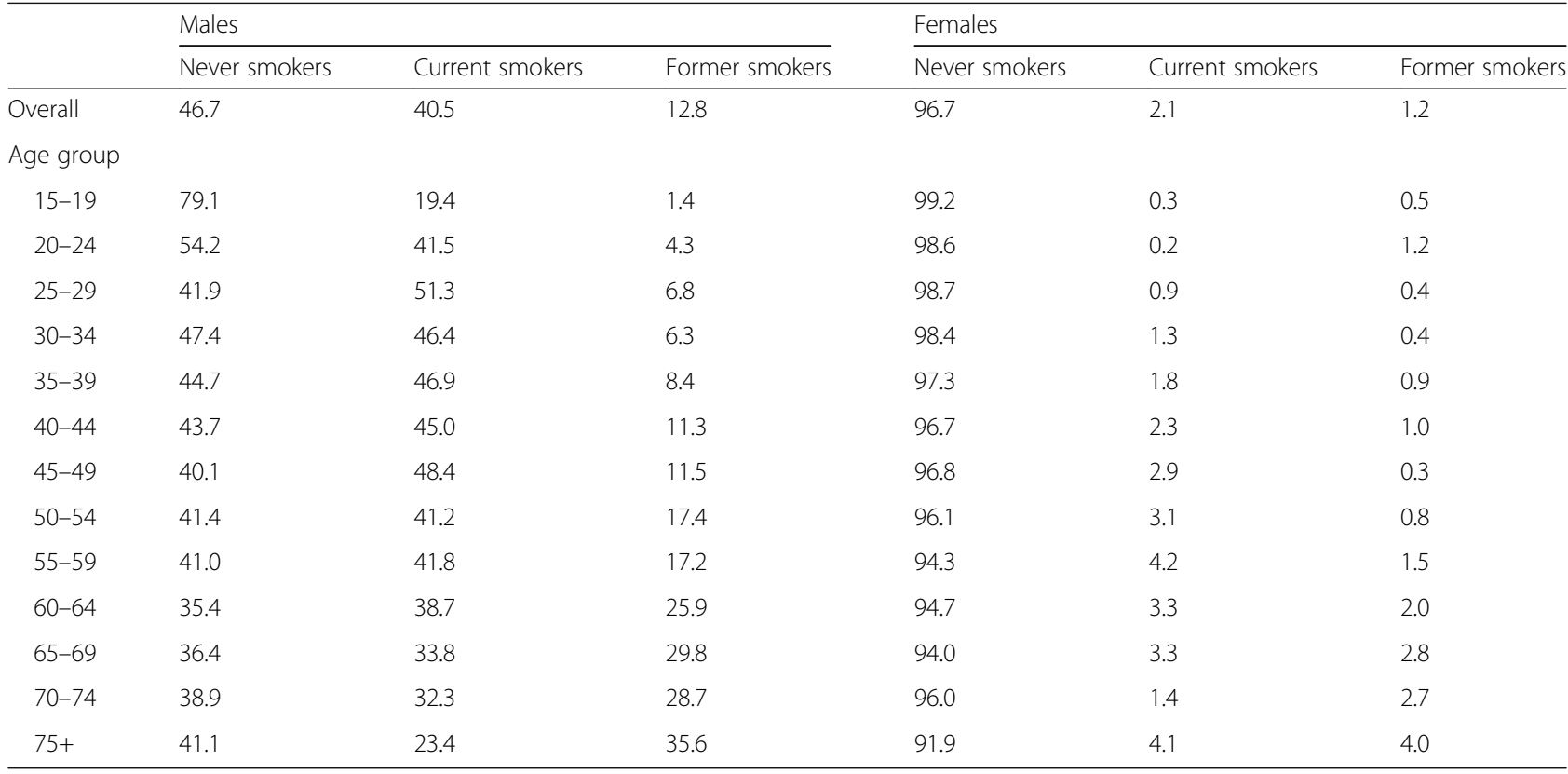

Source: Estimates from the smoking and drinking behavior survey, National Statistics Office

smokers will remain over 10 million due to population growth.

Effects of tobacco control policies on smoking prevalence and deaths

The projected annual smoking prevalence under each of the six scenarios is shown in Fig. 3. From the baseline scenario, the annual 15\% increase in cigarette tax would have the highest contribution (compared with other single interventions) to reducing the male smoking prevalence, with a reduction from $41.7 \%$ in 2010 to $36.1 \%$ in 2025 , which is equivalent to a $4.5 \%$ reduction against the 2025 baseline prevalence or a $13.4 \%$ reduction compared to 2010. The synergistic effects of the combined interventions would reduce the prevalence to $33.7 \%$ in 2025 , which is equivalent to a $10.8 \%$ reduction against the 2025 baseline or a $19 \%$ relative reduction from 2010.

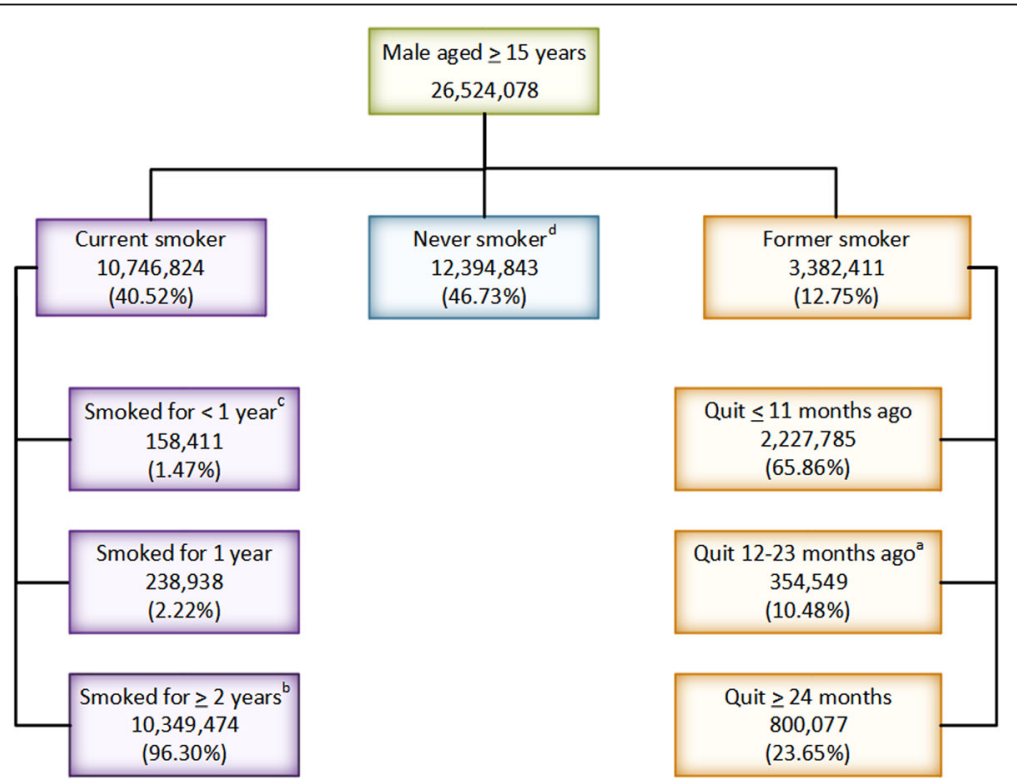

Fig. 2 Number of smokers and quitters among males aged 15 years and over stratified by smoking duration, 2014 (Annual cessation rate $=a /(a+$ b); Annual initiation rate $=c /(c+d))$ 
Table 3 Annual cessation rates in males stratified by age group, 2014

\begin{tabular}{ll}
\hline Age group & Annual cessation rate \\
\hline $15-19$ & $3.3 \%$ \\
$20-24$ & $1.4 \%$ \\
$25-29$ & $1.5 \%$ \\
$30-34$ & $1.3 \%$ \\
$35-39$ & $2.2 \%$ \\
$40-44$ & $2.2 \%$ \\
$45-49$ & $3.0 \%$ \\
$50-54$ & $3.8 \%$ \\
$55-59$ & $6.1 \%$ \\
$60-64$ & $4.8 \%$ \\
$65-69$ & $6.1 \%$ \\
$70-74$ & $7.4 \%$ \\
$75+$ & $13.6 \%$ \\
All ages & $3.3 \%$ \\
\hline
\end{tabular}

While an annual tax increase had the largest impact on smoking prevalence, brief advice showed potent and immediate effects on reduction in smoking attributable deaths with almost 55,000 fewer deaths. Combined interventions resulted in a $4 \%$ reduction. As shown in Table 4 , the cumulative number of deaths over the 10 year period between 2016 and 2025 was 2,235,851 among males aged $>15$ years. By 2025 , a total of 99,784 tobacco related deaths, or $4.5 \%$ of the total deaths from all causes, were projected to be averted by implementing the combined tobacco policies. This follows the brief advice to quit smoking in clinical settings which contributes to $2.46 \%$ of all-cause mortality.

Figure 4 shows the effects of each theoretical scenario on the prevalence of smoking. The projected smoking prevalence under an ideal scenario (maximum combined interventions) in 2025 would reduce the prevalence to $28.5 \%$.

\section{Discussion}

This study applied a Markov chain model to predict the smoking prevalence and attributed deaths in 2025 among males aged 15 years or more based on the impact of different tobacco control policies. Under a baseline scenario where no additional intervention is implemented, the smoking prevalence in males would reduce from $40.8 \%$ in 2015 to $37.8 \%$ in 2025 .

The most effective single policy for reducing the male smoking prevalence was found to be a $15 \%$ annual increase in tobacco tax, a policy which would reduce the prevalence by $4.5 \%$ in 2025 . Implementation of a comprehensive combination of all tobacco control policies would reduce the male smoking prevalence by $10.8 \%$ in 2025 and approximately 100,000 deaths could be averted, which is equivalent to a $4.5 \%$ reduction in allcause mortality. The comprehensive combination of tobacco control policies could reduce the male smoking prevalence by $19 \%$ in 2025 , which is well below the global target of $30 \%$.

From 2015 to 2025, the male smoking prevalence in Thailand would decrease from 40.8 to $37.8 \%$ (0.3 percentage points per year) given no additional intervention. Our finding confirms a study by WHO where the male smoking prevalence was projected to decrease from $42.7 \%$ in 2015 to $39.5 \%$ in 2025 , equivalent to an annual reduction of 0.32 percentage points [36]. We projected that combined tobacco control policies would lead to as much as a $19 \%$ relative reduction in the male smoking prevalence by 2025 . The only way to achieve this $30 \%$ reduction would be to assume a 100\% smoking cessation rate and a zero smoking initiation rate, both of which are implausible.

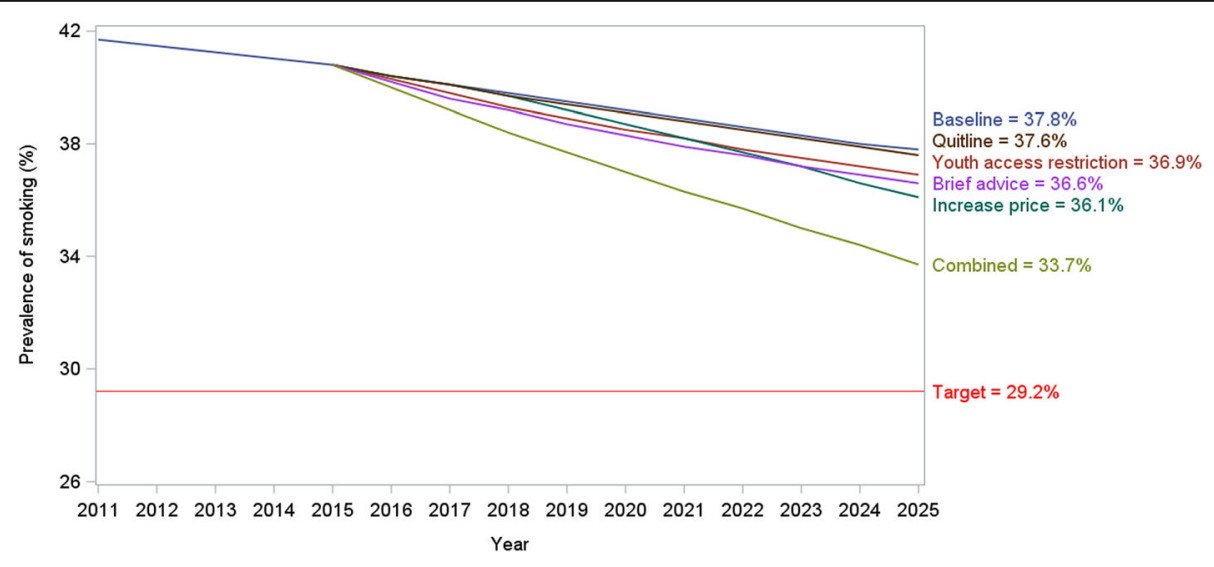

Fig. 3 Effects of different smoking control policies on smoking prevalence in male, 2015 to 2025 
Table 4 Number of baseline and smoking attributed deaths averted from different tobacco control policies, 2016-2025

\begin{tabular}{|c|c|c|c|c|c|c|}
\hline Year & Baseline all-cause deaths (aged $>15$ years) & Restricted access to youth & Price increase & Quit-line & Brief advice & Combined \\
\hline 2016 & 256,947 & 0 & 0 & 0 & 0 & 0 \\
\hline 2017 & 248,268 & 0 & 0 & 0 & 0 & 0 \\
\hline 2018 & 240,143 & 78 & 0 & 78 & 640 & 811 \\
\hline 2019 & 232,517 & 223 & 116 & 206 & 1,686 & 2,290 \\
\hline 2020 & 225,346 & 425 & 423 & 366 & 2,982 & 4,332 \\
\hline 2021 & 218,591 & 674 & 967 & 545 & 4,426 & 6,856 \\
\hline 2022 & 212,219 & 963 & 1,776 & 734 & 5,950 & 9,804 \\
\hline 2023 & 206,200 & 1,286 & 2,866 & 930 & 7,507 & 13,127 \\
\hline 2024 & 200,505 & 1,634 & 4,244 & 1,126 & 9,069 & 16,790 \\
\hline 2025 & 195,115 & 2,001 & 5,909 & 1,320 & 10,612 & 20,759 \\
\hline Cumulative & $2,235,851$ & 9,668 & 24,164 & 6,816 & 54,999 & 99,784 \\
\hline \multicolumn{2}{|c|}{ Reduction in mortality (\%) } & $0.43 \%$ & $1.08 \%$ & $0.30 \%$ & $2.46 \%$ & $4.46 \%$ \\
\hline
\end{tabular}

Taxation on tobacco products has been an effective means of tobacco control in many countries. Our findings are consistent with a recent systematic review of over 100 studies, including a growing number from lowand middle-income countries [21]. This study shows that a 15\% annual increase in cigarette tax yields the highest reduction in smoking prevalence, although such a high tax increase would require extraordinary political leadership amidst a tobacco industry that exerts staunch resistance and political lobbying [37]. The consequences of raising cigarette taxes, such as increased cigarette smuggling and consumption of lower priced cigarettes, [25, 38] would likely dilute the intended effects of this intervention. The tobacco industry takes advantage of this loophole in the ad valorem excise tax system in Thailand to falsely declare a lower imported price. This dilutes the impact of an increased retail price [39]. To overcome this loophole, the actual retail prices should be used as the basis for the ad valorem taxation. This means the tax rate should be based on the retail price, not the reported exfactory or imported price. A combination of ad valorem and specific tax per weight or per cigarette would have a stronger impact on price increases. The Thai government should review the tax rate regularly to keep pace with inflation and the increased capacity of smokers to pay for cigarettes [40].

This study demonstrates that professional brief advice is the second-best policy for reducing the male smoking prevalence and also contributed most to the reduction of smoking attributed deaths. Evidence suggests that a few minutes of brief advice given by health professionals at any clinical encounter can increase the smoking cessation rate [34]. A professional-led brief advice session informing smokers about the harms of smoking is technically very feasible under the universal health coverage system in Thailand as there is a high level of clinical contact between patients and health professionals (Thailand has more than 3.5 outpatient visits per capita per year and an admission rate of more than 11\%) [41]. There are also more than a million village health volunteers throughout the country. The cost of implementing these advice sessions should be low as they can easily be

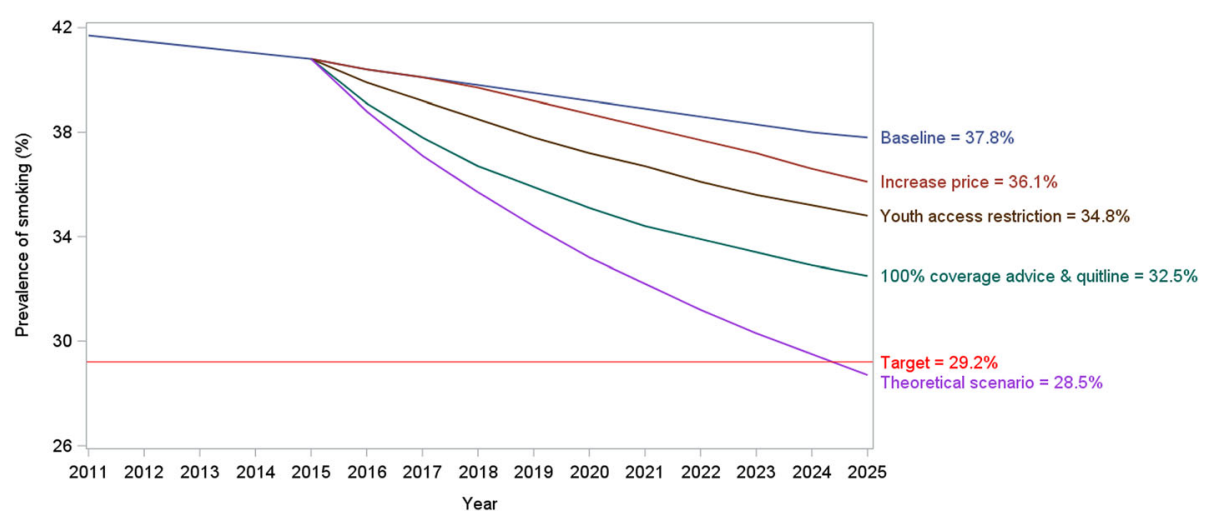

Fig. 4 Effect of smoking control policies on smoking prevalence in males aged 15 years or more under a theoretical ideal scenario, 2015 to 2025 
integrated into existing counseling sessions by health professionals in clinical settings and are well supported by the village health volunteers.

The quit-line program provide behavioral counselling to help callers (smokers and their relatives) to develop and follow a plan to quit smoking. However, it was found have the least impact on reducing the all-cause mortality due to smoking and the program has yet to scale up its performance and coverage of services. New information technologies and social media allow for online transmission of short messages related to quitting and an info-graphic quit smoking program that might increase coverage to half of all target smokers. This policy option should be explored further and implemented at the appropriate scale, not just for Thailand, but for other low- to middle-income countries where there is an inadequate public health infrastructure.

Prevention of smoking initiation among youth is a key to ending the tobacco epidemic in Thailand. We have projected that preventing smoking onset in youth and young adults would reduce the male smoking prevalence in 2025 by $8 \%$. However, the unforeseen consequence of a policy to restrict under-age youth accessing tobacco products has shifted to other means of access such as receiving tobacco from relatives, friends, or even strangers [42]. The 2015 Global Youth Tobacco Survey reported that half of the underage youth had no difficulty in buying cigarettes, reflecting weak regulatory environments and enforcement capacities [13]. Although electronic cigarettes remain illegal in Thailand, 3.3\% of youth were current e-cigarette smokers [13]. These results indicates that enforcement of the existing laws is weak, not only in Thailand, but around the world.

Our comparison of the theoretical ideal and the realistic scenario on smoking cessation interventions illustrated the importance of population coverage. When the quit-line and brief interventions fully cover all smokers, the prevalence reduced by 4 percentage points, although there was a 3.4 times increase in cessation rate (from 22 to $99.2 \%$ ).

\section{Limitations of the study}

Several of our methodological assumptions are likely to have had an effect on the study outcomes. The policy effect sizes depend on underlying assumptions, such as initiation and cessation rates, which both affect the smoking prevalence. Predictors of successful quitting include a lower level of nicotine dependence, a longer duration of time since the last attempt to quit smoking, a higher level of self-efficacy, and an absence of pressure from peer smokers.

Our estimates did not include initiation of new tobacco products, such as electronic cigarettes and policies on smoke free interventions, such as mass media campaigns, advertising bans, and package warning labels. Although these interventions appear to have raised awareness about the dangers of tobacco use, it is difficult to quantify the degree of these effects on tobacco use behavior and health outcomes.

Our results were possibly underestimated because females, due to their low smoking prevalence, were excluded from the analysis. However, the male smoking prevalence is about 20 times that of females. Because of their far greater consumption of tobacco, male smokers have disproportionately higher morbidity and mortality rates.

The excess risk of dying from smoking is a simple model based on the relative risk for current and former smokers. In reality, smoking-related mortality depends on many factors. Our method has low precision in predicting the smoking prevalence because of the limitation in estimating initiation and cessation rates. The relative risks for mortality from smoking were based on data from a US Cancer Prevention study. American mortality risks and tobacco epidemiology may differ from that of the Thai population.

The impacts of tobacco control interventions differ according to demographic and socioeconomic characteristics [43], but these effects are generally reported as national averages across the entire population. Existing studies do not distinguish variation of impacts across population sub-groups. To address this issue, future studies should include the assessments of the impacts on different socioeconomic and geographic parameters.

\section{Conclusion}

Despite modeling limitations, this study confirms that a $15 \%$ cigarette tax increase has the most impact on reducing the male smoking prevalence while brief advice could avert the highest number of smoking related deaths by 2025 . Combined interventions have a synergistic effect with an estimated 99,800 deaths being averted between 2015 and 2025. Despite the decreasing prevalence, the reductions are projected to be insufficient to achieve a $30 \%$ reduction in the prevalence of tobacco smoking by 2025. Increased efforts to control tobacco use will be essential for reducing the burden of noncommunicable diseases in Thailand.

\section{Appendix}

Relative risks (95\% confidence intervals) of all-cause mortality by smoking status, data from Cancer Prevention Study phase II

\begin{tabular}{lll}
\hline & Males & Females \\
Never smoker & 1 & 1 \\
Current smoker & $2.33(2.26-2.40)$ & $2.08(2.02-2.14)$ \\
Former smoker & $1.42(1.38-1.45)$ & $1.33(1.29-1.37)$ \\
\hline
\end{tabular}

Source: American Cancer Society, Cancer Prevention Study phase two [8] 
The following formulas were applied to estimate the probabilities of dying for never, current and former smokers.

$$
M_{x}^{n}=\frac{M_{x, t}^{p}}{\operatorname{RR}_{x}^{c} \times \operatorname{Prev}_{x}^{c}+R R_{x}^{f} \times \operatorname{Prev}_{x}^{f}+1 \times 1-\left(\operatorname{Prev}_{x}^{c}+\operatorname{Prev}_{x}^{f}\right)}
$$

Where

$$
\begin{aligned}
& M_{x, t}^{c}=R R_{x}^{c} \times M_{x}^{n} \\
& M_{x}^{f}=R R_{x}^{f} \times M_{x}^{n}
\end{aligned}
$$

$M_{x}^{n}, M_{x}^{c}, M_{x}^{f}=$ mortality rate for never (n), current $(c)$ and former $(f)$ smokers, respectively in age group $x$.

$M_{x}^{p}=$ mortality rate of the total population $(p)$ in age group $x$.

$\operatorname{Prev}_{x}^{c}, \quad \operatorname{Prev}_{x}^{f}=$ prevalence of current and former smokers, respectively in age group $x$

$R R_{x}^{c}, R R_{x}^{f}=$ relative risk of mortality in current and former smokers, respectively compared to never smokers in age group $x$.

The mortality rates (MR) for never, current and former smokers for age group $x$ were then converted into the probability of dying for age group $x$ using the formula:

$$
\mathrm{P}_{\mathrm{x}}=1-\mathrm{e}^{-\mathrm{MRx}}
$$

\section{Abbreviations}

Cl: Confidence interval; CS: Current smoker; NCDs: Non-communicable diseases; NS: Never smoker; NSO: National Statistics Office; XS: Former smoker

\section{Acknowledgements}

We acknowledge the contributions of National Statistics Office in producing nationally representative surveys for regular monitoring of tobacco consumption in Thailand.

\section{Authors' contributions}

SA and SP designed the study. SA and VT analyzed data and was a major contributor in writing the manuscript. SA, SP, KB, CA, VC, RP and VT commented, revised, finalized, and approved the manuscript.

\section{Funding}

This work was supported by Thai Health Promotion Foundation. The funders had neither role in study design, data collection, analysis, decision to publish, nor preparation of the manuscript.

\section{Availability of data and materials}

The data that support the findings of this study are available from National Statistical Office but restrictions apply to the availability of these data, which were used under license for the current study, and so are not publicly available. Data are however available from the authors upon reasonable request and with permission of National Statistical Office.

\section{Ethics approval and consent to participate}

The study was exempt from ethics approval as it only used secondary data from surveys that had followed conventional ethics guidelines and recorded no personal identifiers.

\section{Consent for publication}

Not applicable.

\section{Competing interests}

The authors declare that they have no competing interests.

\section{Author details}

${ }^{1}$ International Health Policy Program, Ministry of Public Health, Nonthaburi, Thailand. ${ }^{2}$ Tobacco Control Research and Knowledge Management Center, Mahidol University, Bangkok, Thailand. ${ }^{3}$ Epidemiology Unit, Faculty of Medicine, Prince of Songkla University, Songkhla, Thailand.

Received: 20 October 2018 Accepted: 16 July 2019

Published online: 23 July 2019

\section{References}

1. Assembly UG. Political declaration of the high-level meeting of the general assembly on the prevention and control of non-communicable diseases. New York: United Nations; 2011.

2. Kontis V, Mathers CD, Rehm J, et al. Contribution of six risk factors to achieving the $25 \times 25$ non-communicable disease mortality reduction target: a modelling study. Lancet. 2014;384(9941):427-37.

3. Bonita $\mathrm{R}$, Magnusson $\mathrm{R}$, Bovet $\mathrm{P}$, et al. Country actions to meet UN commitments on non-communicable diseases: a stepwise approach. Lancet. 2013:381(9866):575-84.

4. World Health Organization. Noncommunicable diseases country profiles 2018. Geneva: World Health Organization; 2018.

5. Alwan A. Global status report on noncommunicable diseases 2010. Geneva: World Health Organization; 2011.

6. Burden of Disease Thailand. Thailand burden of diseases attributable to risk factors 2014. Nonthaburi: International Health Policy Program; 2017.

7. Bundhamcharoen K, Aungkulanon S, Makka N, Shibuya K. Economic burden from smoking-related diseases in Thailand. Tob Control. 2016;25(5):532-7.

8. Vathesatogkit $\mathrm{P}$, Charoenca N. Tobacco control: lessons learnt in Thailand. Indian J Public Health. 2011;55(3):228-33.

9. National Statistical Office. The smoking and drinking behavior survey 2017. Bangkok: National Statistical Office; 2017.

10. Sangthong R, Wichaidit W, Ketchoo C. Current situation and future challenges of tobacco control policy in Thailand. Tob Control. 2012; 21(1):49-54.

11. Lee $\mathrm{G}$, Lee J, Lee S. Risk factors of future smoking among Thai youth: a secondary analysis of the Thai global youth tobacco survey. Asia Pac Public Health. 2015;27(2):NP2602-9.

12. Lim A, McNeil D. Modeling for demographic and regional prevalence and trends of smoking in Thai males. Southeast Asian J Trop Med Public Health. 2016;47(2):309-17

13. Chotbenjamaporn $P$, Haruhansapong V, Jumriangrit $P$, Pitayarangsarit $S$, Agarwal N, Garg R. Tobacco use among thai students: results from the 2015 global youth tobacco survey. Indian J Public Health. 2017; 61(Suppl 1):S40-6.

14. 2018 Global progress report on implementation of the WHO framework convention on tobacco control. Geneva: World Health Organization;2018.

15. Levy DT, Benjakul S, Ross H, Ritthiphakdee B. The role of tobacco control policies in reducing smoking and deaths in a middle income nation: results from the Thailand SimSmoke simulation model. Tob Control. 2008;17(1):53-9.

16. Hughes JR, Peters EN, Naud S. Relapse to smoking after 1 year of abstinence: a meta-analysis. Addict Behav. 2008;33(12):1516-20.

17. Thun MJ, Carter BD, Feskanich D, et al. 50-year trends in smoking-related mortality in the United States. N Engl J Med. 2013;368(4):351-64.

18. Sirirassamee T, Sirirassamee B. Trends in tobacco use among Thai adolescents. J Med Assoc Thail. 2013;96(Suppl 1):S78-84.

19. Difranza JR. Which interventions against the sale of tobacco to minors can be expected to reduce smoking? Tob Control. 2012;21(4):436-42.

20. Pierce JP, White VM, Emery SL. What public health strategies are needed to reduce smoking initiation? Tob Control. 2012;21(2):258-64.

21. Chaloupka FJ, Yurekli A, Fong GT. Tobacco taxes as a tobacco control strategy. Tob Control. 2012:21(2):172-80.

22. US Department of Health Human Services. Reducing tobacco use: a report of the surgeon general.(2000). Atlanta, Georgia, US Department of Health and Human Services, Centers for Disease Control and Prevention. National Center for Chronic Disease Prevention and Health Promotion, Office on smoking and health Google scholar. 2000. 
23. DeCicca P, Kenkel D, Mathios A. Cigarette taxes and the transition from youth to adult smoking: smoking initiation, cessation, and participation. J Health Econ. 2008;27(4):904-17.

24. Chaloupka FJ, Cummings KM, Morley CP, Horan JK. Tax, price and cigarette smoking: evidence from the tobacco documents and implications for tobacco company marketing strategies. Tob Control. 2002;11(Suppl 1):162-72.

25. Husain MJ, Kostova D, Mbulo L, Benjakul S, Kengganpanich M, Andes L. Changes in cigarette prices, affordability, and brand-tier consumption after a tobacco tax increase in Thailand: evidence from the global adult tobacco surveys, 2009 and 2011. Prev Med. 2017;105(Suppl):S4-S9.

26. Abrams DB, Graham AL, Levy DT, Mabry PL, Orleans CT. Boosting population quits through evidence-based cessation treatment and policy. Am J Prev Med. 2010;38(3 Suppl):S351-63.

27. Cummins SE, Bailey L, Campbell S, Koon-Kirby C, Zhu SH. Tobacco cessation quitlines in North America: a descriptive study. Tob Control. 2007;16(Suppl 1):i9-15.

28. Abrams DB. Comprehensive smoking cessation policy for all smokers: systems integration to save lives and money. In: Ending the tobacco problem: a blueprint for the nation; 2007. p. A1-A45.

29. Fiore $M C$, Jaen $C R$, Baker $T$, et al. Treating tobacco use and dependence: 2008 update. Rockville: US Department of Health and Human Services; 2008.

30. Borland $R$, Li L, Driezen $P$, et al. Cessation assistance reported by smokers in 15 countries participating in the international tobacco control (ITC) policy evaluation surveys. Addiction. 2012:107(1):197-205.

31. Stead LF, Hartmann-Boyce J, Perera R, Lancaster T. Telephone counselling for smoking cessation. Cochrane Database Syst Rev. 2013;8:CD002850.

32. Meeyai A, Yunibhand J, Punkrajang P, Pitayarangsarit S. An evaluation of usage patterns, effectiveness and cost of the national smoking cessation quitline in Thailand. Tob Control. 2015;24(5):481-8.

33. Maciosek MV, Coffield AB, Flottemesch TJ, Edwards NM, Solberg LI. Greater use of preventive services in U.S. health care could save lives at little or no cost. Health Aff (Millwood). 2010;29(9):1656-60.

34. Stead LF, Buitrago D, Preciado N, Sanchez G, Hartmann-Boyce J, Lancaster T. Physician advice for smoking cessation. Cochrane Database Syst Rev. 2013:5.

35. Raw M, Regan S, Rigotti NA, McNeill A. A survey of tobacco dependence treatment services in 36 countries. Addiction. 2009:104(2):279-87.

36. World Health Organization. WHO global report on trends in tobacco smoking 2000-2025. Geneva: WHO; 2015.

37. Chantornvong S, McCargo D. Political economy of tobacco control in Thailand. Tob Control. 2001;10(1):48-54.

38. White JS, Ross H. Smokers' strategic responses to sin taxes: evidence from panel data in Thailand. Health Econ. 2015;24(2):127-41.

39. Smith KE, Savell E, Gilmore AB. What is known about tobacco industry efforts to influence tobacco tax? A systematic review of empirical studies. Tob Control. 2013:22(2):144-53.

40. WHO Regional Office for South-East Asia. Tax policies on tobacco products in Thailand: the way forward. Geneva: World Health Organization, Regional Office for South-East Asia; 2012.

41. National Health Security Office. The National Health Security Annual Report [in Thai]. Geneva: National Health Security Office; 2018.

42. Rimpela AH, Rainio SU. The effectiveness of tobacco sales ban to minors: the case of Finland. Tob Control. 2004;13(2):167-74.

43. Hill S, Amos A, Clifford D, Platt S. Impact of tobacco control interventions on socioeconomic inequalities in smoking: review of the evidence. Tob Control. 2014;23(e2):e89-97.

\section{Publisher's Note}

Springer Nature remains neutral with regard to jurisdictional claims in published maps and institutional affiliations.

\section{Ready to submit your research? Choose BMC and benefit from:}

- fast, convenient online submission

- thorough peer review by experienced researchers in your field

- rapid publication on acceptance

- support for research data, including large and complex data types

- gold Open Access which fosters wider collaboration and increased citations

- maximum visibility for your research: over $100 \mathrm{M}$ website views per year

At $\mathrm{BMC}$, research is always in progress.

Learn more biomedcentral.com/submissions 